\title{
THE USAGE OF ARCS RADII PROFILE VARIATION FOR THE SYNTHESIS OF RAILWAY WHEEL AND RAIL HEAD PROFILES
}

The presented article deals with one of the ways of profile geometry design of a railway wheel and railhead. The base for the creation of new profiles is an interactive attitude based on the modification of "the original shape which is defined by section of a railway wheel profile", with to each other connected and exactly defined arcs radii. It is possible to change them according to shape needs of the final geometrical characteristics.

\section{Introduction}

The wheel/rail geometry is one of the main parameters dramatically influencing track forces and vehicles dynamic. The resulting wheel geometry in service conditions depends upon the new assumed profile, the track geometry distribution, the creep coefficients and forces, the rail average material and mechanics, the wheel material and mechanics, the lubrication. The evolution of wheel profile used to be validated in exemplar application cases, on the basis of available results or through dedicated measuring campaign.

In the article we will deal with the railway wheel/rail contact from the point of view of wheels and rails profiles geometry.

\section{Railway wheel/rail contact in the frame of railway vehicles interoperability request}

Problems of the railway wheel /rail contact represents a basic point of any analysis which is connected with the moment of a railway vehicle on a track, with safety, speed, with comfort of people and goods transport.

It is connected with the construction of new railway vehicles, with the reconstruction of the old ones, with the approval (refusal) of vehicles into operation, with their evaluation as well as with the evaluation of track quality and their maintenance. It has a direct influence on the position of rail transport in the frame of the whole transport system, on economics, ecology and so on.

Profiles shapes (we understand a profile curve course which a rail and wheel have in a lateral cross section, or at a rail in a cross section which is perpendicular on the rail axis and at a wheel with a plane which is crossing the wheel centre point and which is perpendicular on a plane of a wheel lateral cross section) as we know them today have been developing since the beginning of railway.
The shape of wheel tread and rail head profiles has been developed together with the satisfaction of needs on the goods and people transport when looking at the enhancement of wheelset loading for heavy haul transport and speed for passenger and heavy haul transport as well.

Nowadays several basic wheels and rails profiles types are used on various European railways. It depends on a specific railway company of the given country whether one type of rails equipped with a standardised profile or several types of profiles are used in its railway corridors.

The aim of each railway company is (or should be) that the wheel/rail contact couple provides the best presuppositions for a smooth, safe (stable) and quiet vehicle running on a track with a minimum wheels and rail wearing, with a minimum negative force influence of a wheel on the track.

The fact that various types of rails with different types of profiles, with different slopes are used at separate companies complicates the situation. The track gauge complicates it to a smaller degree.

Today there is an extremely up to date need for the security of vehicles interoperability in its greatest extend in order to use in reality one of the greatest advantages of railway transport (economic transport of a huge volume of goods over long distances). The fulfilment of the need places a higher requirement on the sphere of usage (design or choice of the right, for the given railway company so -called optimum profile).

It arises from the variety of inputs and transport needs of separate railway companies that it is not easy at all to find one profile which solves all the problems.

It is possible to use a proved and verified standard in a higher degree when building new modern tracks and railway corridors.

\footnotetext{
* Tomáś Lack, Juraj Gerlici

Department of Transport and Handling Machines, Faculty of Mechanical Engineering, University of Žilina, Univerzitná 8215/1, SK-010 26 Žilina.

E-mail: tomas.lack@fstroj.utc.sk, juraj.gerlici@fstroj.utc.sk.
} 
As a result of real conditions of a railway track in certain European regions at specific utilisation (the way of operation, loading, accessibility, simplicity and economic demands for the track maintenance), it has a sense to adapt, for example, a wheels profile to rail head profiles or for a certain track type to vehicles equipped with a certain wheels profile to find a rails profile which improves a mutual vehicle/rail interaction.

In order to declare a profile or a couple of profiles (wheel/ rail) for a better one than another profiles couple, it is necessary to analyse both the existing and new state on the base of unambiguous criteria.

Such input criteria, after fulfilment of which verification in operation must of course follow, are geometrical characteristics.

When assessing characteristics in the article we take into consideration neither the wheelset rotation around its axis which can happen at a lateral movement of a wheelset in a rail, nor the wheelset angle of attack; their influence in this case seems to be of minimum importance $[4,5]$.

\section{Wheel and rail profiles geometry analysis}

The geometric shape of theoretical wheels and rails profiles is usually defined in a table way, with radii (and centres) of to each other linked arcs, or by functional dependence of a vertical profiles points position with regard to the lateral coordinate $y$.

The profiles acquired from the measurements have a base in points which are determined with couples of coordinates. It is often necessary to smooth such profiles for further assessment.

The role of the smoothing is to keep the profile geometry characteristics and to minimize influence of possible imperfections of measurements. Theoretical profiles are not smoothed. Profiles and arcs radii values from which the profiles are created with regard to the lateral coordinate $y$ are graphically depicted in Fig. 1 and Fig. 2. Theoretical profiles: wheel profile DIN5573 (marked S1002) and rail UIC60 are analysed separately in the figures.

In Fig. 3 there is a course of theoretical wheel profile arcs radii values of S1002 in the contact points with regard to wheelset lateral movement y.

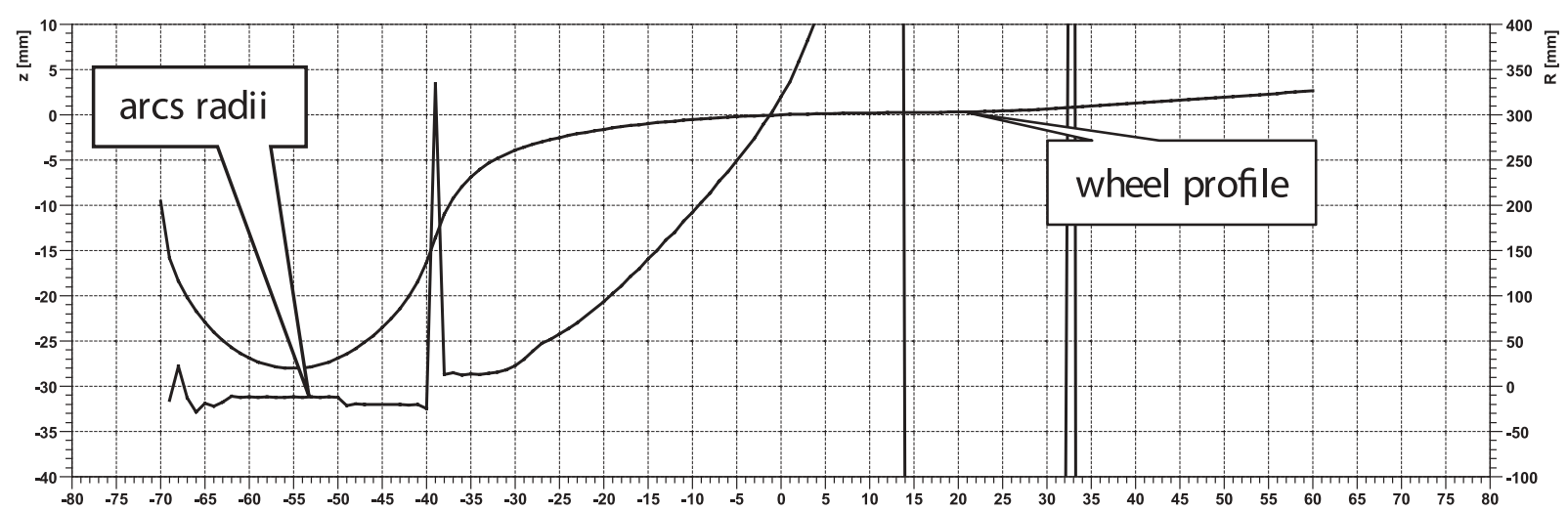

Fig. 1 Course of theoretical wheel profile arcs radii values of $S 1002$ with regard to a lateral profile coordinate $y$

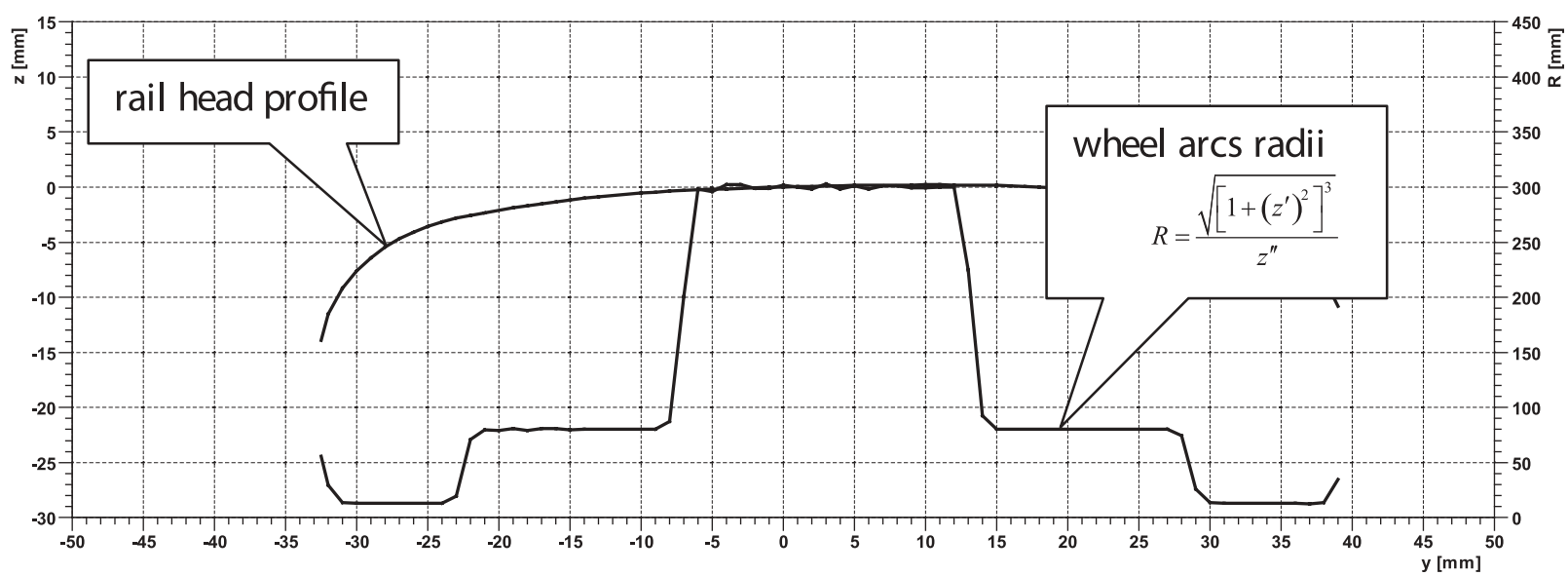

Fig. 2 Course of theoretical rail head profile arcs radii values of UIC60 with regard to a lateral profile coordinate $y$ 
Right profiles radii

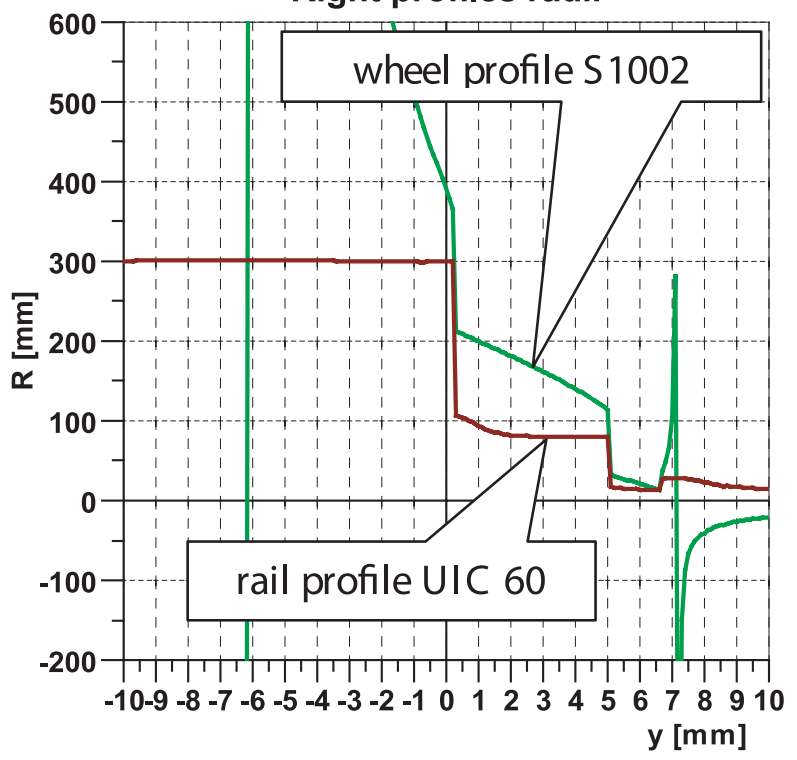

Fig. 3 Course of theoretical wheel profile arcs radii values of $S 1002$ and rail UIC60 in the contact points with regard to wheelset lateral movement $(y)$

\section{Wheelset and rail geometric characteristics}

Wheelset and rail geometric characteristics help to specify the geometric binding of a wheelset and rail. With the help of them, it is possible relatively quickly to assess some parameters of the binding which help to estimate as a vehicle or better to say a wheelset can behave in a real operation.

Under the name of geometric characteristics we understand the following: contact points distribution between a wheel and rail at a lateral movement of wheels profiles of a wheelset over rail heads profiles, delta $r$ function, tangent gamma function and equivalent conicity function. The basic presupposition for the characteristics evaluation is detailed knowledge of a wheel and rail profiles geometric shape.

To make the information complete, it is necessary to mention separate geometric characteristics. On the base of their shape we will suggest a railway wheel profile shape (to the given rail profile) or a rail head profile shape (to the supposed railway wheel shape).

They are as follows:

Contact points between the wheel and rail determine the contact points position at a wheel profile lateral movement over the rail profile. If we can presuppose that left and right wheel profiles (as well as rail profiles) are identical, the final curve course is symmetrical with regard to the rail axis.

Delta $r$ function is a difference between an instant diameter of running of one wheel of a wheelset and instant diameter of running (course) of other wheel of a wheelset at the lateral movement of a wheelset on a rail. The Delta $r$ function course shape indicates the rotating tendency of a wheelset at its lateral movement in a rail or kinematics running ability of a wheelset through the track arc.

Tangens gamma function is a difference between the value of the normal line tangent angle of the tangential contact area in the contact point and vertical axes of a rail. It determines the rate of binding intensity which comes back the wheelset after its lateral deviation into a centred equilibrium position on the rail. The tangent gamma function has (like the delta $r$ function) anti-symmetrical course for the same wheels and rails profiles and it crosses the horizontal coordinate axis in its zero point.

Equivalent conicity is the reference conicity which equals the curving profile of a wheel when taking into consideration the amplitude of a coned wheel movement. According to the definition of UIC519 it is such conicity of a simple cone wheelset profile which the wheelset should possess in order to have the same kinematics characteristics as a wheelset with a curved profile at a certain oscillation amplitude.

It is possible to find more detailed information about separate characteristics, their definitions, meaning and the way of calculation under various possible conditions in references $[4,5,6,9,21]$ of the article.

\section{New optimum profiles statement}

It is not possible to state a generally optimum profile for all types of tracks and railway wheels. The main reason is that in operation there are tracks with various gauges, various rail heads profiles on which vehicles with various railway wheels profiles move. Vehicles move at various speed, with various wheel forces, they transport various goods and more over we require various kinematics behaviour. That is why it is very difficult to state unambiguous criteria which we could define and compare when taking into account all vehicles.

We have chosen geometric characteristics of a railway wheelset and rail, we will state our optimum real or rail profile on the base of their specific shape.

\subsection{Criteria for the search of an optimum profile}

We have stated the following conditions as criteria for optimizing process:

- delta - r function shape without jump change of the course,

- requested equivalent conicity,

- fluent distribution of contact points on the wheel and rail surface,

- exclusion of two- point- contact

The difference function course shape (delta-r) without jumps indicates continual increase in lateral forces in the wheel and rail contact point without kick bounces and additional dynamic exciting of the vehicle mechanical system. This phenomenon is shown on the value of safety against derailment. 
The size of instant equivalent conicity value is connected with the size of wavelength of periodic oscillation movement which a wheelset performs. A low conicity value presupposes a higher wavelength value. Sufficient wavelength size is extremely important for a high-speed railway operation. The size of equivalent conicity is projected into the stability of vehicle movement and riding comfort of passengers.

The determining value of equivalent conicity is stated at the movement amplitude of $3 \mathrm{~mm}$.

Contact points distribution across the profile has a crucial influence on wearing (resistance against wearing) of wheel and materia and at the same time the geometric stability of their profiles.

From the nature of the way of geometrical characteristic evaluation it is clear that it is not possible to suggest profile geometry directly on the base of contact points position setting. Various authors $[1,17,20,23]$ have applied various procedures where continual profile shape modification on the base of a geometric characteristic was the starting point.

\subsection{Profiles creation method through arcs radii profile variation}

We used the method of arcs radii profiles variation for the creation of new profiles which are suitable for the given criteria.
The base of the activity is an interactive attitude which is based on the modification of the original shape defined by parts of railway wheel profile with to each other linked exactly defined arcs radii which can be changed according to the need for the final geometric characteristics shape.

\subsubsection{Arcs radii profile variation}

The basic procedure is as follows:

1. We have the profile of the rail of UIC 60 1:40.

2. We have a requested shape of geometric characteristics: it is low equivalent conicity $\leq 0.05$ in the given case.

3. We choose a "suitable" wheel profile: we will choose the up to now used profile of S1002.

4. We perform numerical division of the whole existing wheel profile in order to obtain simple geometric parts, (depicted in Fig. 4).

5. We create the radii function $R(y)$ (in dependence on the lateral wheel profile coordinate), (depicted in Fig. 5).

6. We set the starting conditions in the equation (10): in the given example, it is the first derivation = tangent value in the starting point $=0.05$.

7. We change the selected radius (from the original S1002 profile radii) and compute the equation (3).

When the new profile is derived, the geometric characteristics are evaluated and the results are assessed. If the results meet our

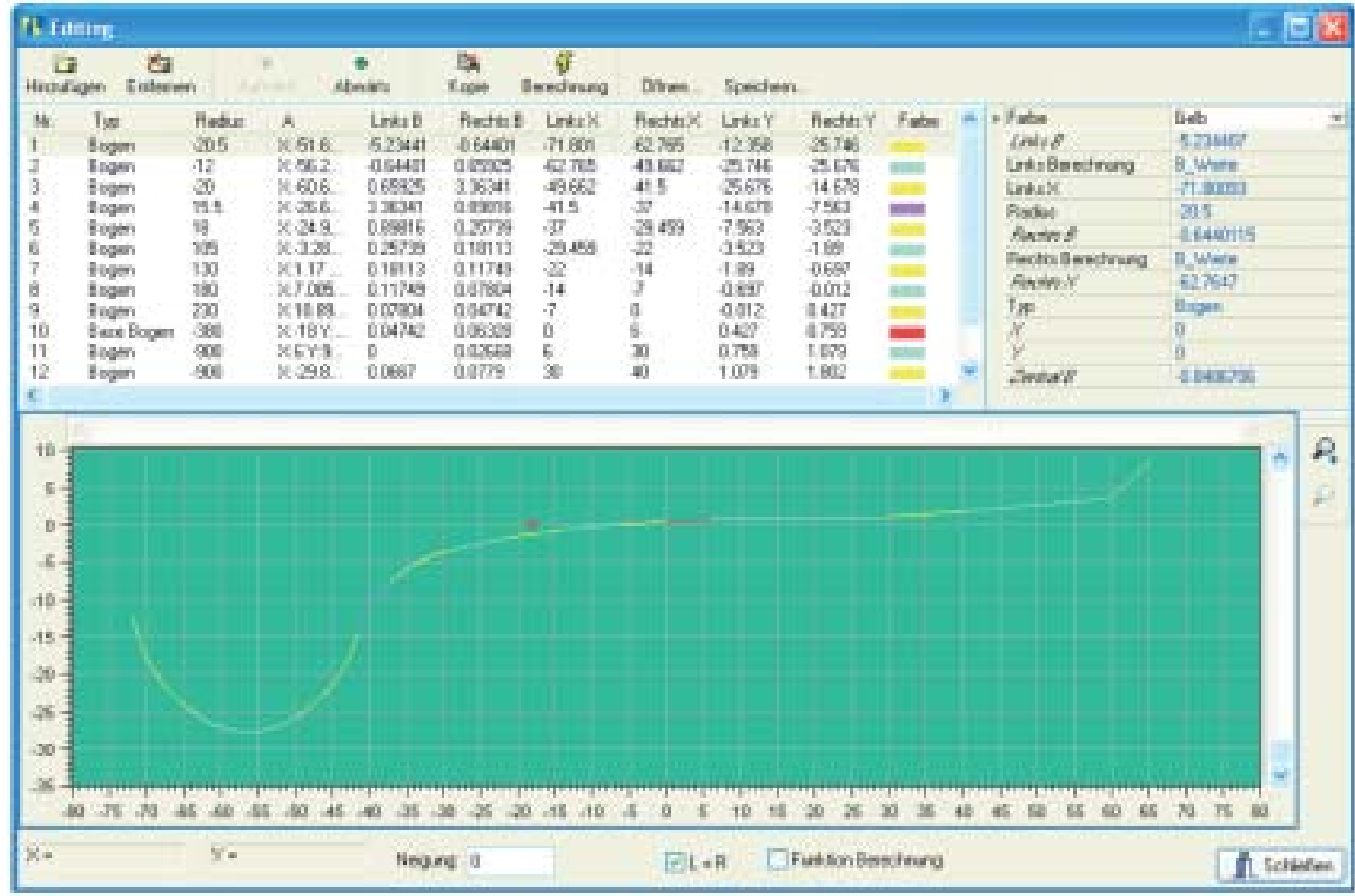

Fig. 4 Wheel geometry profile radii setting 
expectations, the profile is accepted, if the results do not fulfill our expectations, the selected radius (radii) is (are) changed and computations have to continue. In this case, there is a need for knowledge and for experience and skills in the radius selection and radius value for the determination of the change.

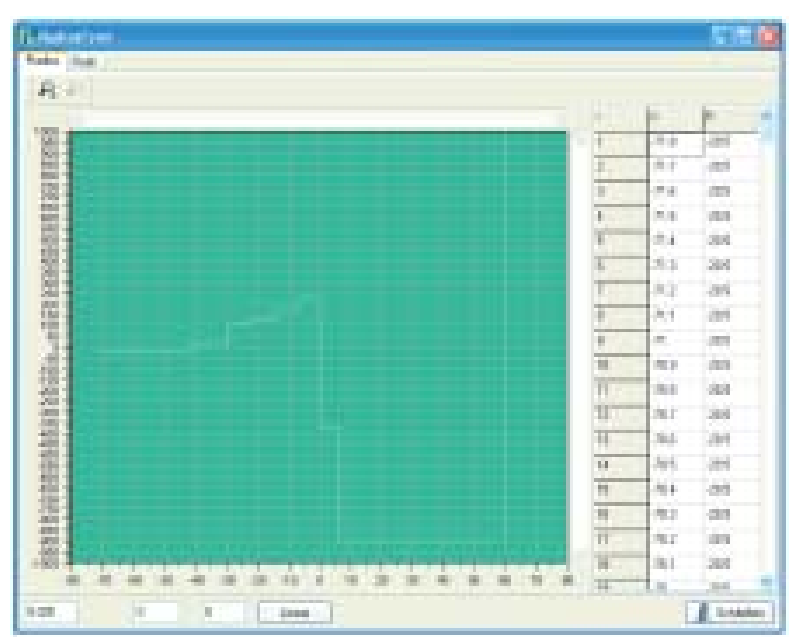

Fig. 5 Arcs radii values course of the suggested wheel profile

\subsubsection{Profile creation on the base of the given functional dependence of radii depending on the coordinate $y$}

Nyström method which is described in the relationship from 4 to 7 was used for the solution of the differential function (3) arising from the relationship for curvature. Its application for the solution of the function (3) is in relationships (8) and (9). The starting conditions are defined in the equation (10).

The radii function $\mathrm{R}$ depends on the lateral movement $\mathrm{y}, \mathrm{z}$ is a vertical profile coordinate.

$$
\begin{aligned}
& R=R(y) \\
& \frac{1}{R(y)}=\frac{z^{\prime \prime}}{\left[1+\left(z^{\prime}\right)^{2}\right]^{3 / 2}} \\
& z^{\prime \prime}=\frac{\left[1+\left(z^{\prime}\right)^{2}\right]^{3 / 2}}{R(y)}
\end{aligned}
$$

Basic relationships for the solutions of a differential function by Nyström method

$$
\begin{aligned}
& k_{1}=f\left(y_{m}, z_{m}, z_{m}^{\prime}\right) \\
& k_{2}=f\left(y_{m}+\frac{h}{2}, z_{m}+\frac{h}{2} \cdot\left(z_{m}^{\prime}+\frac{h}{4} \cdot k_{1}\right), z_{m}^{\prime}+\frac{h}{2} \cdot k_{1}\right) \\
& k_{3}=f\left(y_{m}+\frac{h}{2}, z_{m}+\frac{h}{2} \cdot\left(z_{m}^{\prime}+\frac{h}{4} \cdot k_{1}\right), z_{m}^{\prime}+\frac{h}{2} \cdot k_{2}\right)
\end{aligned}
$$

$$
\begin{aligned}
& k_{4}=f\left(y_{m}+h, z_{m}+h \cdot\left(z_{m}^{\prime}+\frac{h}{2} \cdot k_{3}\right), z_{m}^{\prime}+h \cdot k_{3}\right) \\
& k=\frac{1}{6} \cdot\left(k_{1}+k_{2}+k_{3}\right) \\
& k^{\prime}=\frac{1}{6} \cdot\left(k_{1}+2 \cdot k_{2}+2 \cdot k_{3}+k_{4}\right)
\end{aligned}
$$

$k_{n}$ are auxiliary variables for determination of profiles points vertical coordinate,

$h$ is computational step, we used $h=0.005 \mathrm{~mm}$.

$$
\begin{aligned}
& y_{m+1}=y_{m}+h \\
& z_{m+1}=z_{m}+h \cdot\left(z_{m}^{\prime}+h \cdot k\right) \\
& z_{m+1}^{\prime}=z_{m}^{\prime}+h \cdot k^{\prime}
\end{aligned}
$$

An application of Nyström method for the solution of the equation (3)

$$
\begin{aligned}
& k_{1}=\frac{\left[1+\left(z_{m}^{\prime}\right)^{2}\right]^{3 / 2}}{R\left(y_{m}\right)} \\
& k_{2}=\frac{\left[1+\left(z_{m}^{\prime}+\frac{h}{2} \cdot k_{1}\right)^{2}\right]^{3 / 2}}{R \cdot\left(y_{m}+\frac{h}{2}\right)} \\
& k_{3}=\frac{\left[1+\left(z_{m}^{\prime}+\frac{h}{2} \cdot k_{2}\right)^{2}\right]^{3 / 2}}{R \cdot\left(y_{m}+\frac{h}{2}\right)^{3}} \\
& k_{4}=\frac{\left[1+\left(z_{m}^{\prime}+h \cdot k_{3}\right)^{2}\right]^{3 / 2}}{R\left(y_{m}+h\right)}
\end{aligned}
$$

The initial conditions:

$$
\begin{aligned}
& z\left(y_{0}\right)=z_{0} \\
& z^{\prime}\left(y_{0}\right)=z_{0}^{\prime}
\end{aligned}
$$

were specified in the following way:

$$
\begin{aligned}
& y_{0}=0 \\
& z_{0}=0 \\
& z_{0}^{\prime}=t g \text { profile tangent slope }
\end{aligned}
$$

The initial condition secures that the beginning of the profile coordinate system is placed in a horizontal direction into the plane 


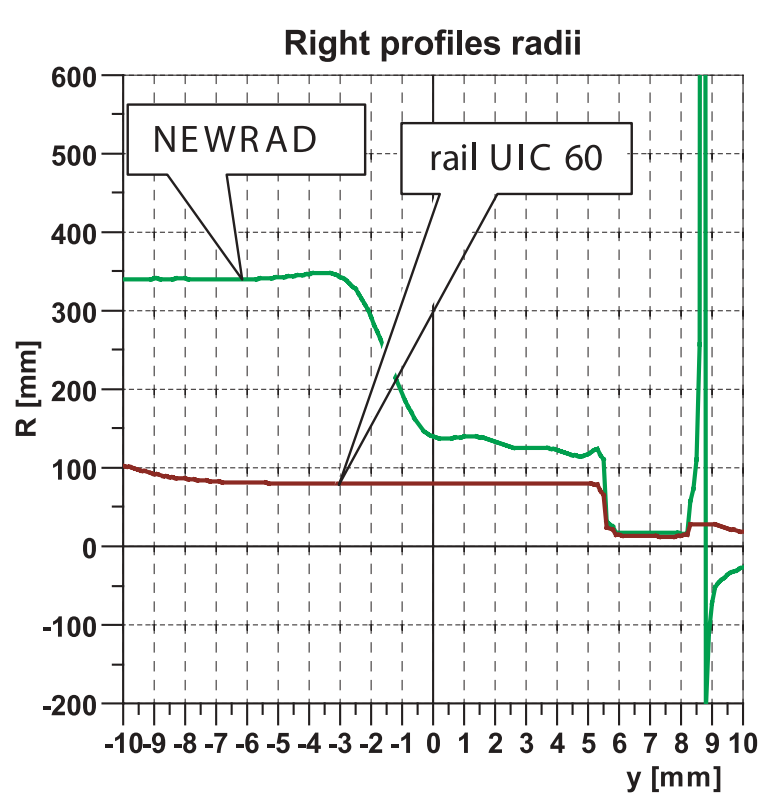

Fig. 6 Profiles radii NEWRAD and UIC60 at contact points of the nominal wheel radii circle and the profile crosses the beginning.

The first $z_{0}^{\prime}$ coordinate derivation determines the tangent value of the profile tangent slope in the point $\left[y_{0}, z_{0}\right]$. The profile is created by the solution of the differential equation (3) continually from the point $\left[y_{0}, z_{0}\right]$ to the left side and then from the point $\left[y_{0}, z_{0}\right]$ to the right side.

\subsubsection{Results of application of the chosen method}

The wheel profiles (NEWRAD) corresponding to our needs thanks to their properties were created on the base of the chosen input parameters at the defined optimizing criteria.

\subsection{Arcs radii profile variation for the creation} of an outer rail profile for a track in a left arc

It is possible to create a rail profile (NEWRAIL) in the similar way like the wheel profile (NEWRAD) was created. Let us suppose

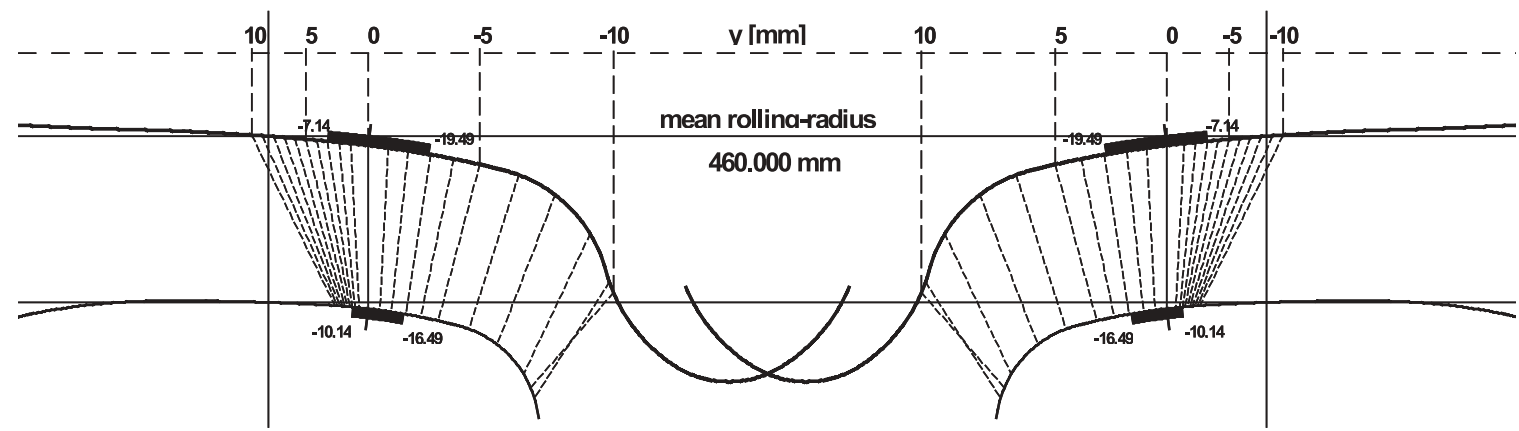

Fig. 7 Contact points at profiles combination NEWRAD/UIC60/1:40/1435 with marking of contact points interval at a wheelset lateral movement in a rail with amplitude of $3 \mathrm{~mm}$

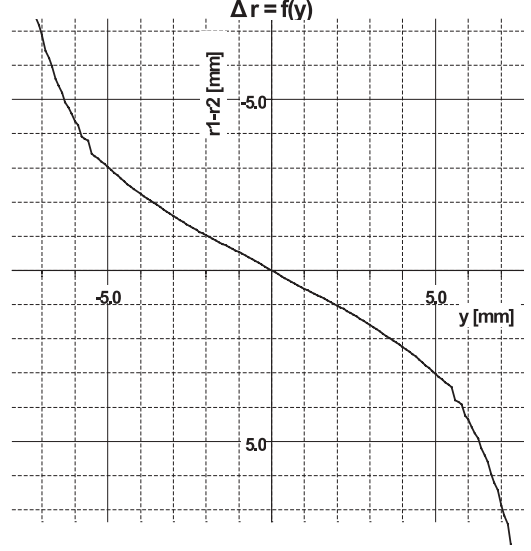

Fig. 8 Delta r function for the profiles combination NEWRAD/UIC60/1:40/1435

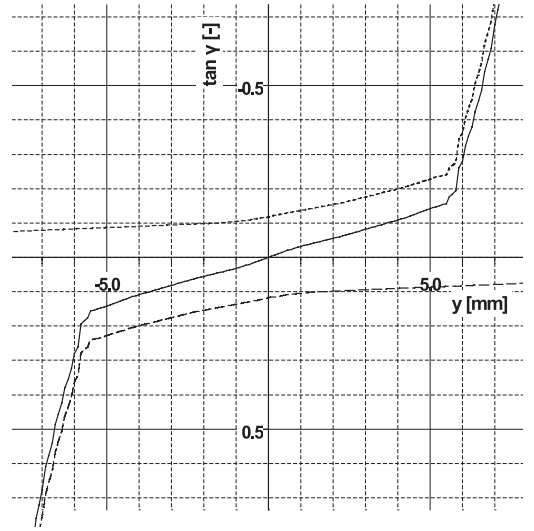

Fig. 9 Tangent gamma function for profiles combination NEWRAD/UIC60/1:40/1435

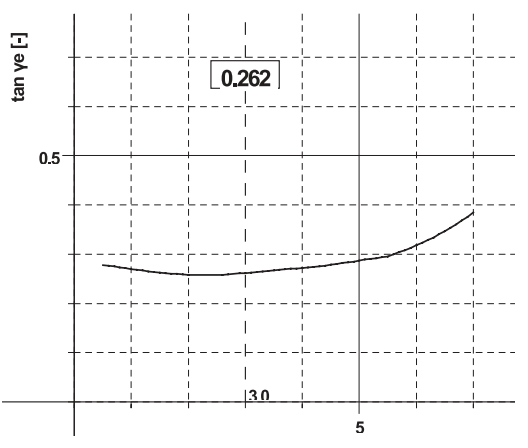

Fig. 10 Equivalent conicity function for the profiles couples NEWRAD/UIC60/1:40/920/1435 


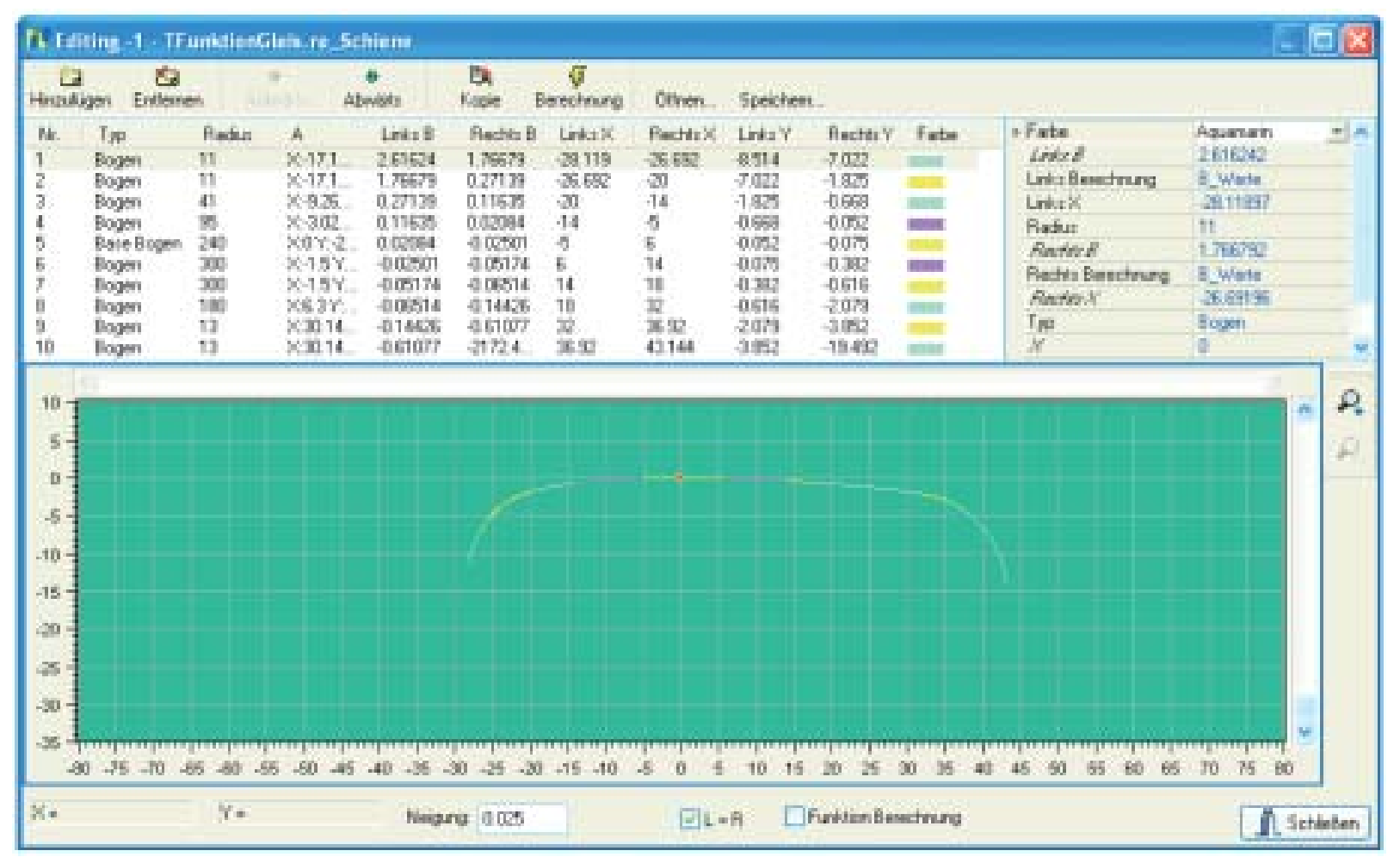

Fig. 11 Dialog window for geometry radii setting of separate rail profile parts

that it is necessary to create an outer rail profile for a track in a left arc in order to fulfil the basic criteria.

We require the following criteria for the new profile: fluent distribution of contact points at a wheelset lateral movement in a rail, no jump course changes of the difference delta r function, low equivalent conicity, the best possible wheelset kinematics movement ability even in the case of small arcs at a small lateral movement, exclusion of two-point-contact. The principal objective of the activity is similar to the one at the wheel profile, it is an inter-

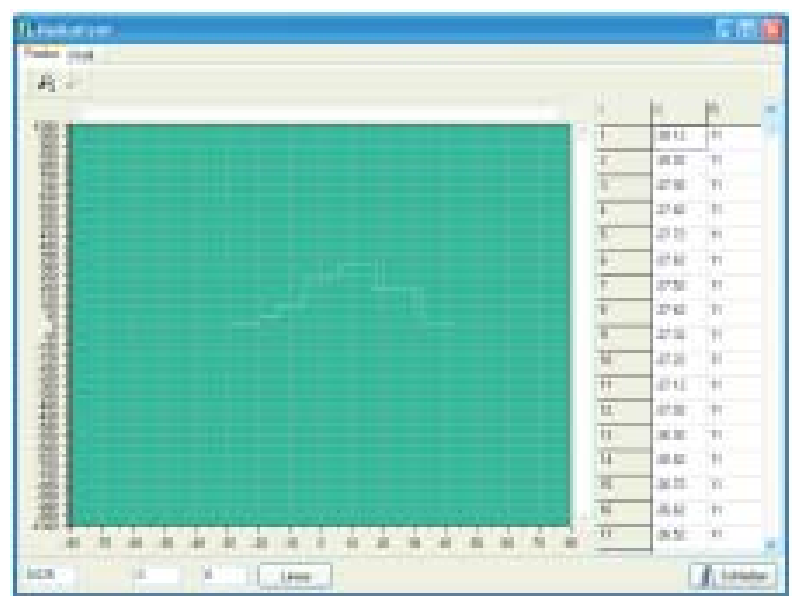

Fig. 12 Depiction of rail head profile arcs at contact points active attitude based on the modification of the "original shape" which is defined by rail profile parts with to each other linked exactly defined arcs radii. It is possible to change the radii size according to the need of a final geometric characteristics shape. The basic profile is divided into parts with precisely defined geometry (radius). The radii function which is dependent on (see part 3 ) is created.

We will modify the function. The differential equation (3) is solved. We set the initial conditions which place the profile into the beginning of the coordinate system and tilt it in this point according to our needs. We calculate the points position of the new profile. We calculate the geometric characteristics. If the shape of the characteristics is not suitable we modify the radii function and repeat the procedure.

INNERRAIL is an inner rail, NEWRAIL is an outer rail of the track. We suggest and analyse the profile for the outer rail.

It is clear from Fig. 17 that the wheel equipped with the S1002 profile can move in a kinematic way through the rail arc radii with an outer rail profile NEWRAIL with the value of approximately $600 \mathrm{~m}$. This happens at the given configuration already at zero lateral displacement. It can move in a kinematic way through the radius smaller than $150 \mathrm{~m}$ at lateral displacement of $5 \mathrm{~mm}$. It is not possible when combining the wheel profile $\mathrm{S} 1002$ and the profile UIC60 (Fig. 18). 
kOMN NikCle
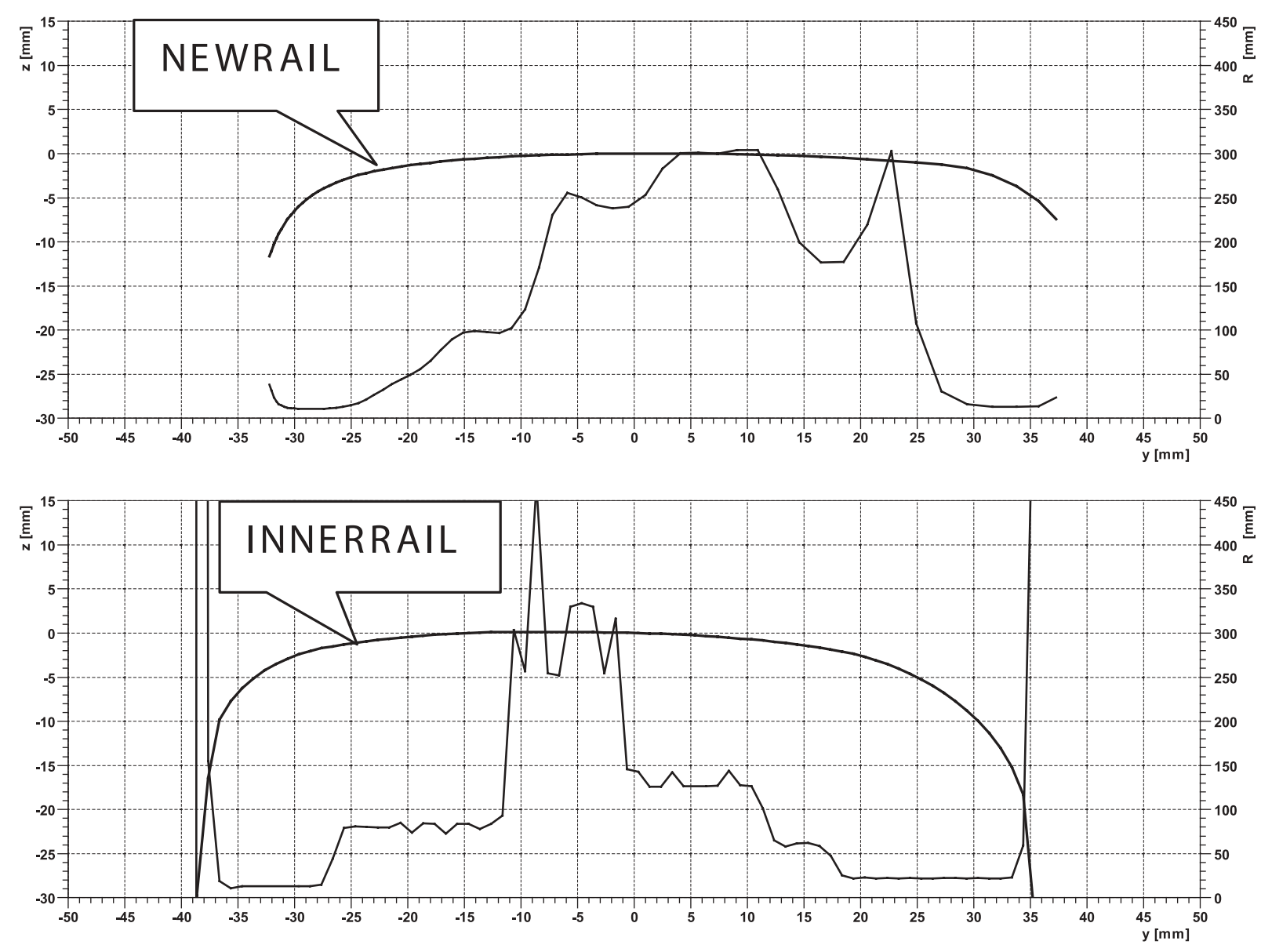

Fig. 13 Profiles and profiles radii NEWRAIL and INNERRAIL

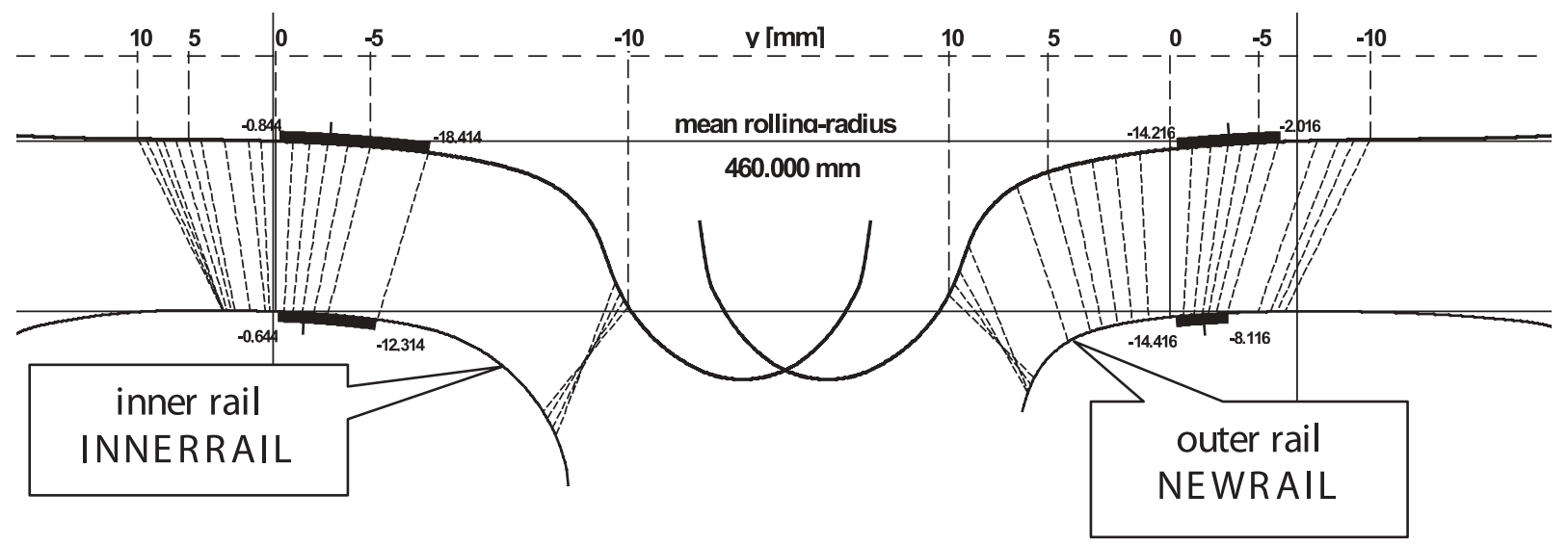

Fig. 14 Depiction of wheelset contact points with profiles $S 1002$ and rails profiles INNERRAIL a NEWRAIL 


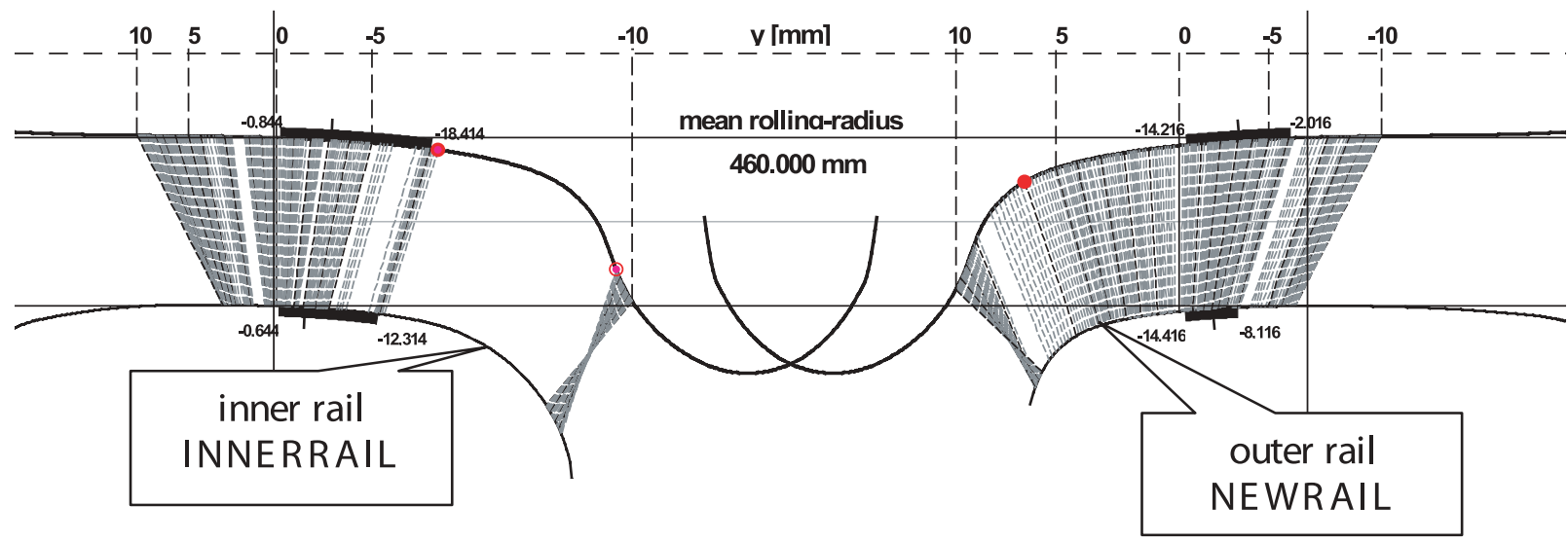

Fig. 15 Detailed view of wheelset contact points distribution with profiles $S 1002$ and rail profiles

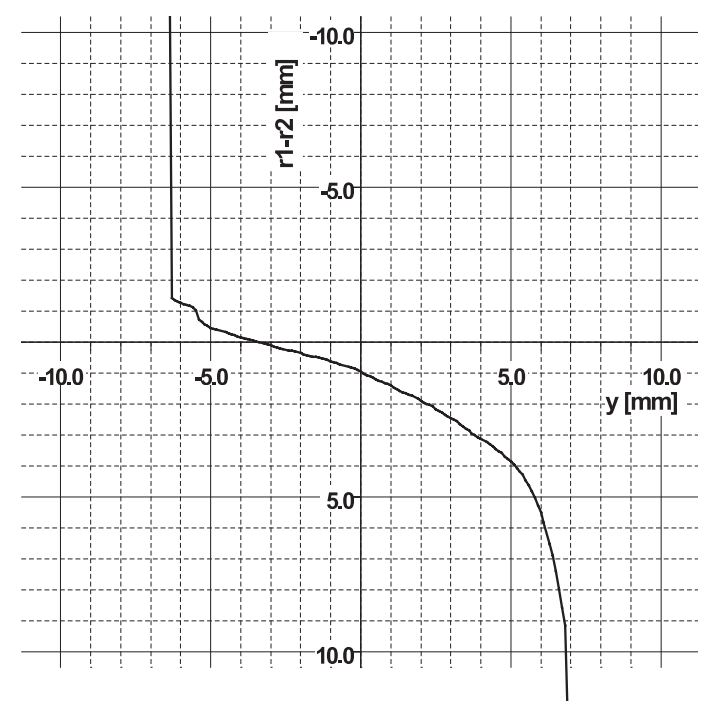

Fig. 16 Delta r function for the given profiles configuration

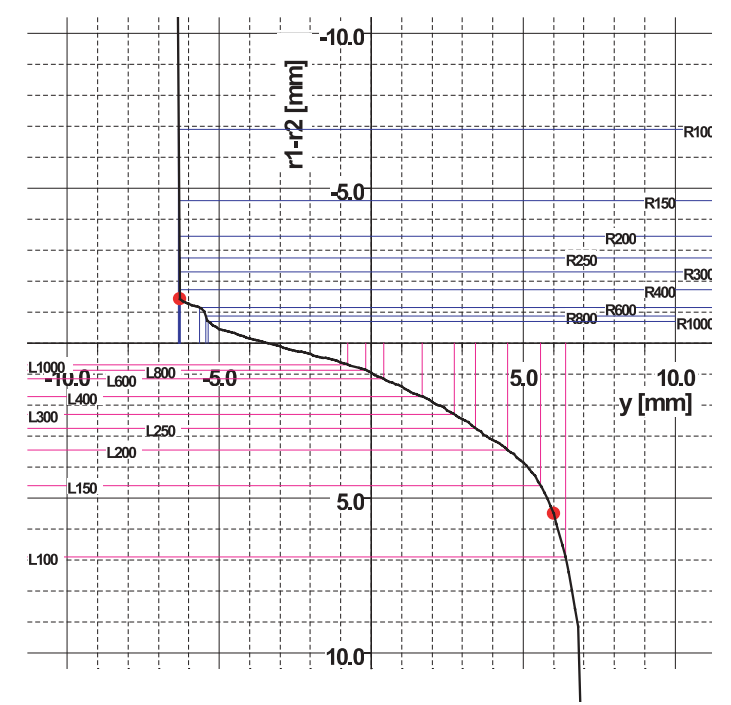

Fig. 17 Delta r function with marked radii for a kinematic movement through a track arc for the rail profile NEWRAIL and wheel profile S1002

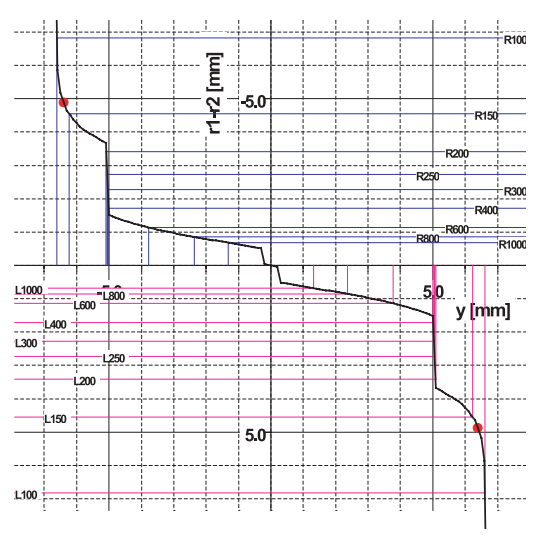

Fig. 18 Delta $r$ function with marked radii for a kinematics movement through a track arc for the rail profile UIC60 and wheel profile S1002

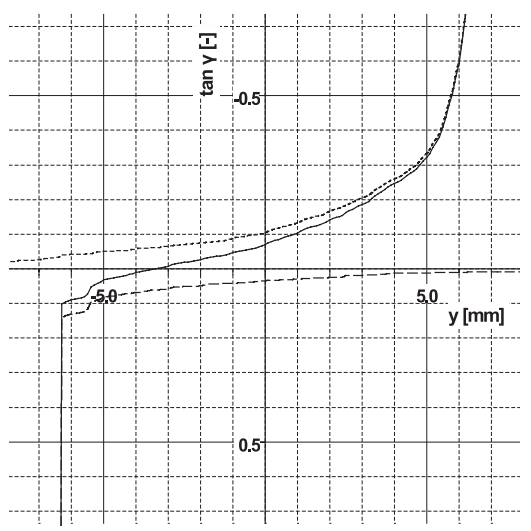

Fig. 19 Tangent gamma function for the given profiles configuration

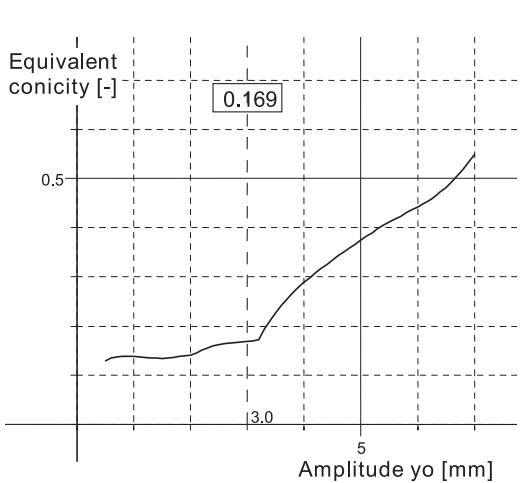

Fig. 20 Equivalent conicity 
The tangent gamma function in Fig. 19, similarly like the delta $r$ function, has the horizontal axis cross section point shifted against the beginning of the coordinate system.

\section{Conclusions}

The article deals with one of the ways of profile geometry design of the railway wheel and rail, or rail head profile on the base of the chosen criteria. On the base of the geometric characteristic shape definition we suggested a railway wheel profile shape (to the given rail profile) NEWRAD and a railhead profile shape (to the supposed railway wheel shape) NEWRAIL.

So from the above mentioned arises that the wheel profiles NEWRAD with characteristics according to Fig. 7-10 and the rail head profiles NEWRAIL with characteristics according to Fig. 14-20 (excluding Fig. 18) are the solution for the following criteria: fluent distribution of contact points at the wheelset lateral movement in a rail, no jump course changes of the difference delta $r$ function, low equivalent conicity, the best possible wheelset kinematics movement ability even in the case of small arcs at a small lateral movement, exclusion of two-point-contact.
The profiles on the base of the assessed characteristics represent an approach to an optimum solution for certain presupposed operational conditions and required manner of vehicle running.

A profile with different geometry will be a result in a case of change of initial parameters which can be represented, for example, by a change of geometry of one from contact couple profiles or a change of vehicle operation manner (a need for different equivalent conicity).

\section{Acknowledgement}

The work was supported by the Scientific Grant Agency of the Ministry of Education of the Slovak Republic and the Slovak Academy of Sciences in Project No. 1/3169/06 "Properties Research of Rail Vehicles in Movement with Emphasis on the Solution of a Wheel and Rail Contact at the Wheelset Rolling in the Rail via Computer Simulation" and in Project No. 1/2116/05: "Interdisciplinary Solution of Modern Rail Transport Means by Usage of Virtual Models and Experimental Methods".

Translation: PaedDr. Marta Kadorová

\section{References}

[1] BERGANDER, B., DENDL, G., NEFTZGER, A., NICKLISCH, D.: Die Entwicklung von Rad- und Schienenprofilen. In: ZEVrail Glasers Annalen 127. Str. 482-503. Georg Siemens Verlagsbuchhandlung, 2003.

[2] BUBMANN, C., NEFTZGER, A.: Die Entwicklung von Schienenprofilen unter dem Einfluß von Verschleiß und die Auswirkungen auf das quasistatische Kurvenlaufverhalten eines Fahrzeuges. In: VDI Berichte NR.820, Systemdynamik der Eisenbahn, 1990.

[3] GERLICI, J., LACK, T.: Railway wheel and rail geometry influence on ride properties of the vehicle. (In Slovak) 16. International conference "Current problems in rail vehicles - PRORAIL 2003", EDIS - Publishing house of University of Žilina, 2003.

[4] GERLICI, J., LACK, T.: Railway wheelset and track contact. (In Slovak) Monograph, p. 200, ISBN 80-8070-317-5, EDIS - Publishing house of University of Žilina, 2004.

[5] GERLICI, J., LACK, T. at.: Transport Means properties Analysis. Vol. I. Monograph, p. 214, ISBN 80-8070-408-2. EDIS - Publishing house of University of Žilina, 2005.

[6] GERLICI, J., LACK, T., KADOROVÁ, M.: Calculation of the Equivalent Conicity Function with a Negative Slope. Communications - Scientific papers of the University of Žilina, 2/2004, pp. 49-56, ISSN 1335-4205, EDIS - Publishing house of University of Žilina, 2004.

[7] HAYASHI, T, TOYAMA, M., HINO, K., ISA, M.: Development of wheel tread nicknamed "CS Tread" for narrow gauge lines. In: World congress on railway research Tokyo, Japan. Pp. 195-198., 1999.

[8] IZER, J.: Effective and equivalent conicity of the wheel tread profile of railway wheelset. (In Czech) In: PRORAIL'95 Current problems in rail vehicles. VŠDS Žilina, 1995.

[9] LACK, T., GERLICI, J.: Contact area and normal stress determination on railway wheel / rail contact. Communications - Scientific papers of the University of Žilina, 2/2005, pp. 38-45, ISSN 1335-4205, EDIS - Publishing house of University of Žilina, 2005.

[10] LACK, T., GERLICI, J.: Profiles synthesis through radii variation of arcs profile. (In Slovak). Current problems in Rail Vehicles. Pp. 115-135. ISBN 80-7194-780-6. DFJP UP, DP Česká Třebová 2005.

[11] LEHNA, H., THEILER, A.: Radprofiloptimierung bei der Verkehrsbetrieben Zürich. (2003) In: Rad Schiene. Pp. 42-50. 6. Internationale Schienenfahrzeugtagung, Dresden, 2003.

[12] MÜLLER, R.: Die Problematik der Berührungsgeometrie Rad/Schiene. In: ZEV+DET Glas. Ann. 118, 3 März, Georg Siemens Verlagsbuchhandlung, 1995.

[13] MÜLLER, R.: Zusammenwirken von Rad- und Schienenprofilen. In: Rad Schiene 2003. Pp. 30-34. 6. Internationale Schienenfahrzeug-tagung, Dresden, 2003.

[14] NEFTZGER, A.: Geometrie der Berührung zwischen Radsatz und Gleis. ETR - Eisenbahntechnische Rundschau, DK 681.938:625.1/.2.031.3, Heft 3. Pp. 113-122, 1974.

[15] PREN 13715:1999, Bahnanwendungen, Radsätze und Drehgestelle, Räder - Radprofile. Deutsche Fassung prEN 13715:1999. 
[16] RIEČANOVÁ, Z. AT AL.: Numerical methods and mathematical statistics. (In Slovak). University textbook. 063-559-87 NMA. Alfa Bratislava, 1987.

[17] SASAKI, K., KAGEYAMA, K., ASANO, K., OKUMURA, M.: Development of the wheel tread profile for commuter train (Investigation of the wear profile of the wheel tread and the rail head. (2000) In: Proc. the 5-th International Conference on Contact Mechanics and Wear of Rail/Wheel Systems CM2000 (SEIKEN Symposium No. 27), pp. 265-270, Tokyo.

[18] SÁGA, M., LETRICH, M., KOCÚR, R.: An Analysis of Vehicle Vibration with uncertain system parameters. Communications Scientific papers of the University of Žilina, 1/2005, pp. 16-21, ISSN 1335-4205, EDIS - Publishing house of University of Žilina, 2005.

[19] SCHEUNEMANN, E., KOLBE, T., MÜLLER, R.: Geometrie Rad /Schiene, ein gemensames Thema für Fahrzeug und Fahrweg. In: ZEV+DET Glas. ZEVrail Glasers Annalen 129, Tagungsband SFT Graz 2005. Pp. 168-189. Georg Siemens Verlagsbuchhandlung, 2005.

[20] SHEN, G., AYASSE, J., B., CHOLLET, H., PRATT, I.: A unique design method for wheel profiles by considering the contact angle function. In: Proc. Instn. Mech. Engrs. Vol 217 Part F.: J. Rail and Rapid Transit. F01902, pp. 25-30. IMechE, 2003.

[21] UIC CODE 519: Method for determining the equivalent conicity. (2003) Draft of January 2003 Original version, 2003.

[22] UIC-KODEX 510-2 VE: Wagen. Bedingungen für die Verwendung von Rädern verschiedener Durchmesser in Laufwerken unterschiedlicher Bauart. 4. Ausgabe. Übersetzung, Oktober 2002

[23] WALENTA, R., HAIGERMOSER, A.: Berührungsgeometrie von Rad und Schiene. Neue Methoden zur Untersuchung und Optimierung. In: ZEV+DET Glas. Ann. 121 (1997) Nr. 2/3 Februar, Georg Siemens Verlagsbuchhandlung, 1997. 